\title{
TIME MANAGEMENT STRATEGY AND ITS RELATIONSHIP WITH THE ACADEMIC ACHIEVEMENT OF STUDENT'S OF AL ZAIEM A L AZHARI UNIVERSITY,FACULTY OF EDUCATION, MODEL
}

\section{Istanbul / Türkiye}

p. $152-173$

Received: $15 / 11 / 2021$

Accepted: 06/12/2021

Published: 01/01/2022

This article has been scanned I iThenticat No plagiarism detected

\author{
Amani AWADALLA ${ }^{1}$
}

\begin{abstract}
:
The study addressed the field of educational management, it aimed to know the relationship between management strategy and academic achievement of science class students of the Faculty of Education at Al Zaeim Al Azhari university.The researcher followed the descriptive method, the sample was (94) of the students, the questionnaire was used as a tool of data collection, the data was analyzed by the statistical package of the social sciences (SPSS), (T) test, the one way analysis of variance( ANOVA), Person correlation, chi-squared test and ( MAN-WHITENY)

The researcher came to many results, the most important:

There was no statistically significant differences attributable to the gender, housing and major variables, there is appositive statistical correlation between dimensions of time management and Grande Point Average (GPA), there was an inverse negative correlation between time management waster and the Grade Point Average(GPA) of the students.

Through what the researcher's came to as results, she recommended:

The necessity of holding training workshops on the importance of time in the student's academic and social life at Al Zaeim Al Azhari university, introducing courses on all levels of education on time management and its strategy.
\end{abstract}

Key words: Al Zaeim Al Azhari University Management Strategy, Academic Achievement.

http://dx.doi.org/10.47832/2717-8293.15.11

1 iD Dr. , AL Zaiem A L Azhari University, Sudan, amaniawadalla888@ gmail.com, https://orcid.org/0000-0002-7306-2814 


\section{استراتيجية إدارة الوقت وعلاقتها بالتحصيل الدراسي لدى طلاب جامعة الزعيم الأزهري، كلية التربية أنموذجا}

\section{أماني مختار عوض الله محمد 2}

تناول البحث مجال الإدارة التربوية وهدف لمعرفة العلاقة بين استراتيجية إدارة الوقت والتحصيل الدراسي لدى

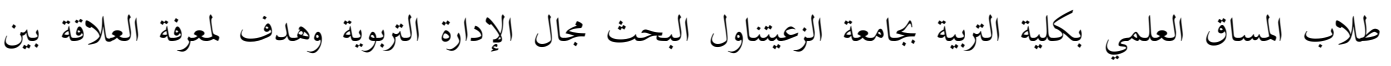
استراتيجية إدارة الوقت والتحصيل الدراسي لدى طلاب المساق العلمي بكلية التربية بجامعة الزعيم الأزهري.

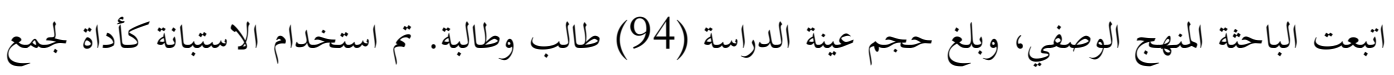

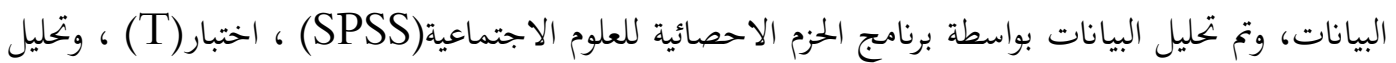

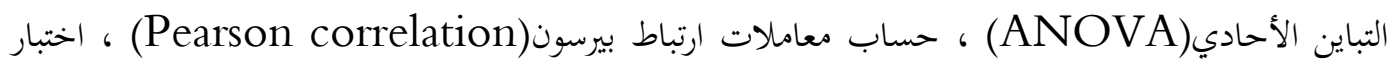
كاي تربيع، مان -وتني. (MAN-WHITNEY) ومن ثم توصلت الباحثة للعديد من النتائج من أهمها: لا توجد فروق ذات دلالة احصائية تعزي لمتغير الجنس، السكن او التخصص، توجد علاقينة ارتباطية طردية موجبة

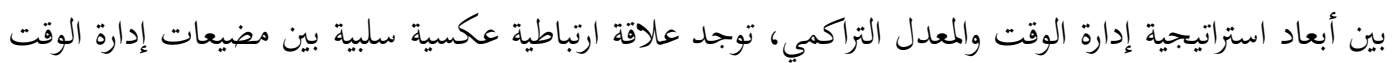
والمعدل التراكمي لدي الطلاب. من خلال ما توصلت إليه الباحثة من نتائج قد أوصت بالعديد من من التوصيات من أهمها: ضرورة عقد ورش تدريبية حول أهمية الوقت في حياة الطالب الأكاديمية والاجتماعية بجامعة الزعيم الأزهري.، إدخال مقرر دراسي بجميع مراحل التعليم يختص بإدارة الوقت واستراتيجياته.

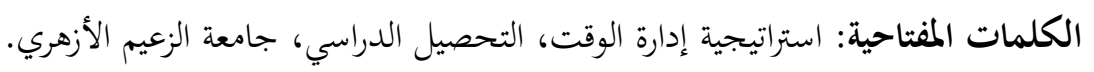

إن العصر الحديث يسمى بعصر السرعة، مما أدي إلى وجود صراع دائم في عملية اللحاق بالزمن لتحقيق الاهداف من قبل الأفراد والجماعات. ونجد ان المشكلة الحقيقية تكمن في إدارة الوقت وليست في الوقت نفسه، فهناك من يحسن إدارة وقته بفاعلية ويستطيع ان ينجز الكثير من الاعمال بينما نجد هنالك من يهدر وقته دون فائدة، لذا يعد الوقت مورد مهم يجب الاستفادة منه والمحافظة عليه.

وتعتبر استراتيجية إدارة الوقت من أهم العوامل التي تؤدى إلى تحسين مستوي التحصيل الدراسي لدي الطلاب الجامعيين

من خلال تقسيم الوقت بين حياتم الأكاديمية والاجتماعية ولا يتأتى ذلك إلا من خلال إدراكهم لأهمية الوقت وحسن وإدئ وإدارته. ومن ناحية اخرى يعد الطالب من أهم العناصر التي تعتمد عليها العملية التعليمية في تحقيق أهدافها، وخاصة الطالب

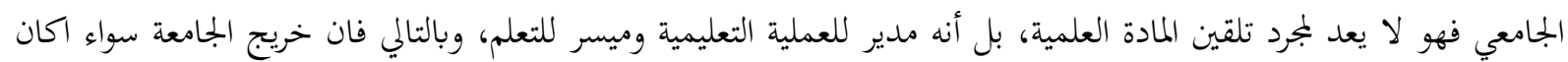


في العمل المهني بأنواعه المختلفة بشكل عام، أم في الحقل التربوي عند ممارسته لمهنة التدريس، فلا ينبغي أن يمارسها إلا بعد ان يعد

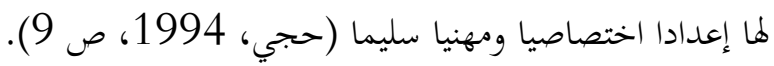
ويتضح من كل ما ذكر ان الوقت يعتبر أحد فنون الحياة، إذ أن إدارته وتنظيمه وحسن استغلاله أهم فن يجب أن يتعلمه

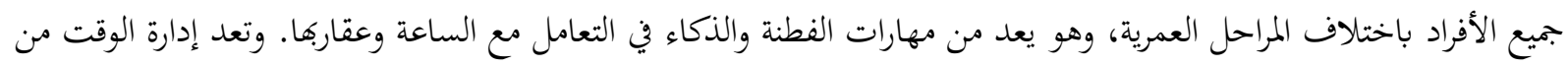

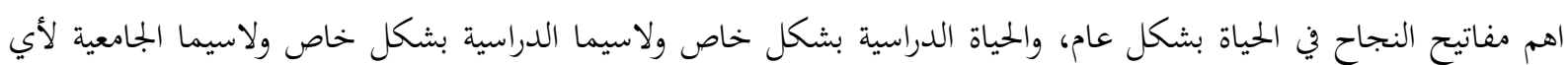
نشاط يقوم به الطالب الجامعي فلابد من تعلم بعض المهارات لتنظيم الوقت التي تمدف إلى تزويد الطالب ببعض الاستراتيجيات

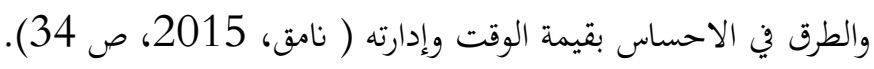

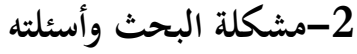

من خلال عمل الباحثة في بجال التدريس الجامعي لاحظت قلة اهتمام الطلاب بأهمية إدارة الوقت بفاعلية وما يترتب على ذلك من مشكلات تصاحب تحصيلهم الأكاديمي ومن هنا انبثت مشكلة البحث الحالية في الكشف عن عن استراتيجية إدارة الوقت

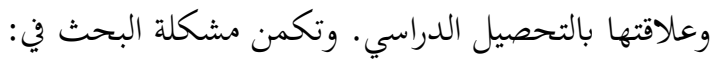

$$
\text { السؤال الرئيس التالي: - n }
$$

هل توجد علاقة ارتباطية بين استراتيجية إدارة الوقت والتحصيل الدراسي لدي طلاب المساق العلمي بكلية التربية بجامعة

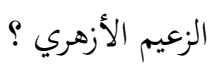

وتتفرع من السؤال الرئيس الاسئلة الفرعية التالية: 1- هل توجد فروق ذات دلالة إحصائية في أبعاد استراتيجية إدارة الوقت لدى طلاب المساق العلمي بكلية التربية جامعة الزعيم الأزهري تعزى لمتغير الجنس ؟ 2- هل توجد فروق ذات دلالة إحصائية في أبعاد استراتيجية إدارة الوقت لدى طلاب المساق العلمي بكلية التربية جامعة الزعيم الأزهري تعزى لمتغير التخصص ؟ هون دات 3-هل توجد فروق ذات دلالة إحصائية في أبعاد استراتيجية إدارة الوقت لدى طلاب المساق العلمي بكلية التربية جامعة الزعيم الأزهري تعزى لمتغير السكن؟ 4-هل توجد علاقة ارتباطية طردية موجبة بين أبعاد استراتيجية إدارة الوقت والمعدل التراكمي لدى طلبة المساق العلمي بكلية التربية جامعة الزعيم الأزهري؟ 5-هل توجد علاقة ارتباطية عكسية سلبية بين مضيعات إدارة الوقت لدى طلبة المساق العلمي بكلية التربية جامعة الزعيم

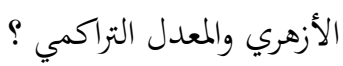
6-هل توجد فروق ذات دلالة إحصائية في المعدل التراكمي لدى طلبة المساق العلمي بكلية التربية جامعة الزعيم الزهري تعزى

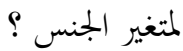

$$
\text { تكمن أهمية هذا البحث في الآتي: }
$$

1-قلة الدراسات التي تتم بموضوع استراتيجية إدارة الوقت لدى طلبة الجامعات الحكومية وغير الحكومية 1- لفت انتباه طلاب جامعة الزعيم الأزهري لأهمية إدارة الوقت وكيفية استثماره. 
3-لفت الانتباه لإدارة الذات من خلال إدارة الوقت بفاعلية لدى طلاب كلية التربية بجامعة الزعيم الأزهري. 3- لفت انتباه الطلاب لمضيعات الوقت بكلية التربية بجامعة الزعيم الأزهري. 4-الخروج بنتائج وتوصيات قد يستفيد منها المسؤولين في توجيه برامج تنمية استراتيجيات إدارة الوقت. لترئ.

\section{4-أهداف البحث:}

1__معرفة الفروق ذات دلالة إحصائية في أبعاد استراتيجية إدارة الوقت لدى طلاب المساق العلمي بكلية التربية جامعة الزعيم الأزهري تعزى لمتغير الجنس. 2 ـ معرفة الفروق ذات دلالة إحصائية في أبعاد استراتيجية إدارة الوقت لدى طلاب المساق العلمي بكلية التربية جامعة الزعيم الأزهري تعزى لمتغير التخصص. 3_ معرفة الفروق ذات دلالة إحصائية في أبعاد استراتيجية إدارة الوقت لدى طلاب المساق العلمي بكلية التربية جامعة الزعيم الأزهري تعزى لمتغير السكن. 4- الكشف عن وجود علاقة ارتباطية طردية موجبة بين أبعاد استراتيجية إدارة الوقت والمعدل التراكمي لدى طلبة المساق العلمي بكلية التربية جامعة الزعيم الأزهري. 5_ الكشف عن وجود علاقة ارتباطية عكسية سلبية بين مضيعات إدارة الوقت والمعدل التراكمي لدى طلبة المساق العلمي بكلية التربية جامعة الزعيم الأزهري. 6- معرفة الفروق ذات الدلالة الإحصائية في المعدل التراكمي لدى طلبة المساق العلمي بكلية التربية جامعة الزعيم الزهري يعزى

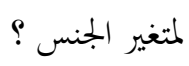

\section{5-منهج البحث:}

اتبعت الباحثة في هذا البحث المنهج الوصفي التحليلي.

\section{6-حدود البحث:}

الحدود الموضوعية: تتمثل في عنوان البحث استراتيجية إدارة الوقت لدي طلاب كلية التربية بجامعة الزعيم الأزهري

$$
\begin{aligned}
& \text { الحمدود المكانية: تتمثل في كلية التربية جامعة الزعيم الأزهري } \\
& \text { الحدود الزمانية: للعام 2020-2021م }
\end{aligned}
$$

\section{7-مصطلحات البحث:}

1-الوقت: هو العامل المشترك بين جميع الناس ويختلفون في كيفية استغلاله ويعود ذلك إلى طبيعة ثقافتهم ومهمتهم واهدافهم

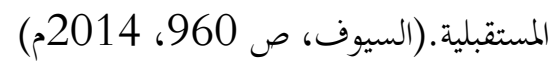

2-2إدارة الوقت:العملية التي توزع الوقت بفعالية بين المهام المختلفة، وذلك بهدف انجازها في الوقت الملائم والمحدد، وبذلك يتكون

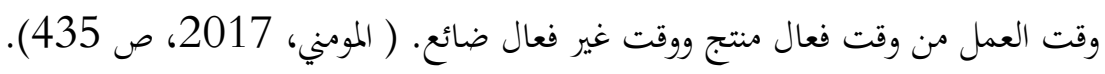


3-استراتيجية إدارة الوقت: بمفهومها الواسع تعرف بأغا:الإدراك الواعي بفن استخدام الوقت، والمعرفة العملية بكيفية استغلاله

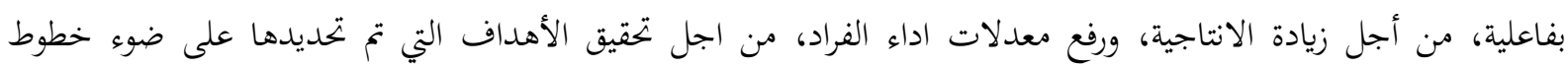

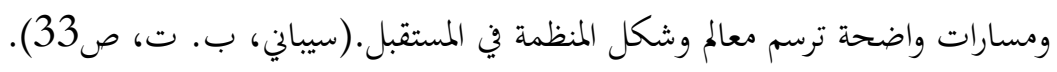

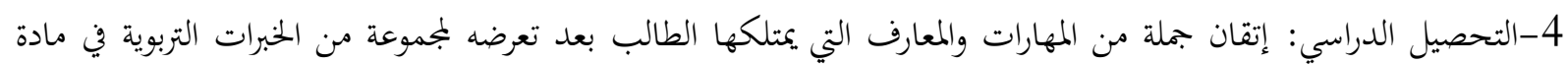

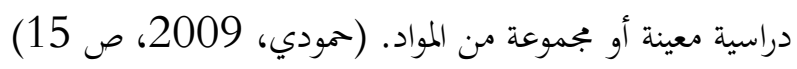
5-التحصيل الدراسي: المعدل التراكمي للطالب الذي يتم احتسابه من خلال الوسط الحسابي لجميع المقررات التي درسها الطالب مقسوما على عددها (اماني مختار، تعريف اجرائي) 6-طلاب جامعة الزعيم الأزهري. هم الطلاب المنتسبون إلى كلية التربية بجامعة الزعيم الأزهري ويدرسون بها حسب النسائي الظمة الجامعة ولوائح التعليم العالي. ( أماني مختار، تعريف اجرائي) 7- جامعة الزعيم الأزهري:احدى الجامعات السودانية الحكومية. ( اماني مختار، تعريف اجرائي الجياتي) 
الفصل الثاني

1- 1 الإطار النظري والدراسات السابقة

- تمهيد:

في هذا الفصل تقوم الباحثة بعرض الإطار النظري الذي يتكون اولا من ثلاث مباحث، المبحث الأول إدارة الوقت أما المبحث

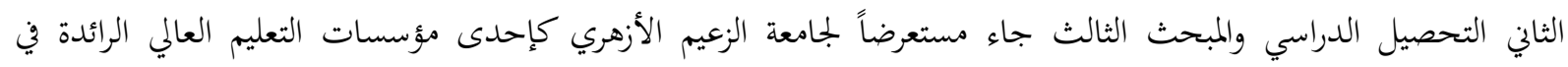
السودان ثم ثانياً الدراسات السابقة.

\section{المبحث الأول}

مدخل:

يتسم هذا العصر بسرعة الايقاع ويعتبر عنصر الوقت واستراتيجية إدارته هي الفيصل في كيفية الاستفادة من الوقت دون

هدo.

وأشارت خلفان ( خلفان،، ص48) بأنه لكي نحصل على معنى واضح لاستراتيجية إدارة الوقت فهي عكس معنى التشويش والاضطراب، وحياة الفوضى وانعدام الرقابة والاستغراق في الحاضر والتصرف وفق الافعال وردود الافعال وغياب الرؤية

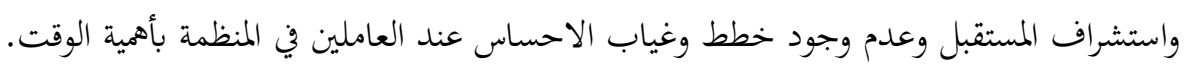

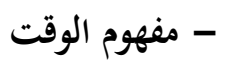

لغة:هو مقدار من الزمان، وكل شيء قدرت له حينا، وأقدرت غايته فهو مؤقت، والوقت من الدهر المعروف (الأنصاري،

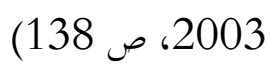

و الوقت اصطلاحا عرفه سلامة (1988، ص16) بأنه وحدة قياس لدوران الارض حول محورها وحول الارض، بحيث

$$
\text { يمثل اليوم 24ساعة والشهر } 30 \text { يوما والسنة 12شهرا. }
$$

بينما يرى الصرفي( 2003، ص12) أن مفهوم الوقت يطلق على عملية تخطيط وتنظيم ورقابة الوقت بما يمكنا من

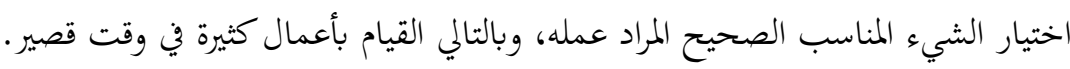

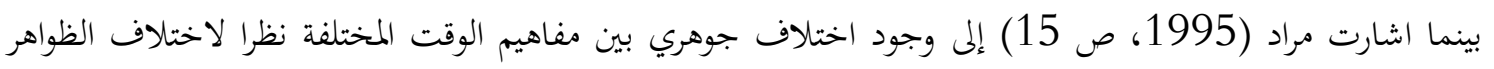
التي تشير اليها هذه المفاهيم وفقا لتصنيف الظواهر الكونية الموجودة، وبناء على هذا الاختلاف استعرض سلاد سلامة ( ص16) خمسة مفاهيم مختلفة للوقت وهي كما اوردها على النحو التالي:

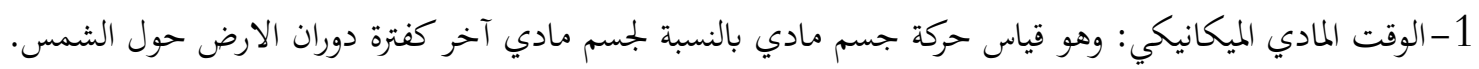

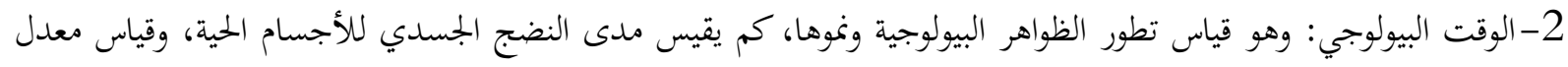
نمو الجسم بيولوجيا.

3-الوقت النفسي: وهو شعور داخلي يعتمد على طبيعة الظرف او الحدث الذي يعيشه الفرد وحالته النفسية.

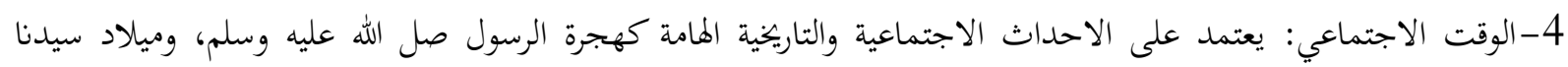

$$
\text { المسيح عليه السلام. }
$$

5- الوقت الميتافيزيقي: او عالم ما وراء الطبيعة ولا نعلم عنه سوى ما ورد في الكتب السماوية عن الحساب والخلود والأزل وغيرها. 


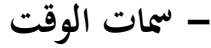

$$
\text { كما اوردةما فضيلة(2008، ص 30) كما يلي: }
$$

ا - رأس مال ينفد وليس دخلا يتجدد، ويتناقص بالسحب الحتمي الذى لا مفر منه، ولا توجد و سيلة لإيقافه او زيادته او

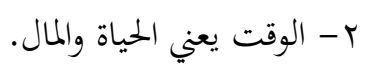

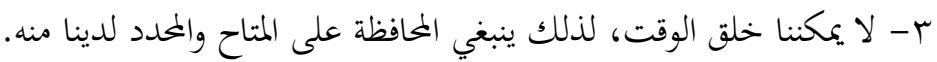

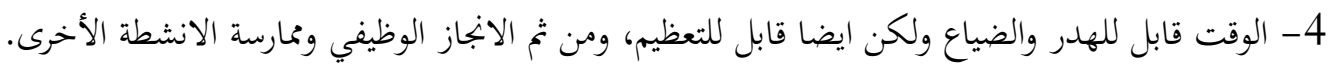
5-الوقت غير مرن ولا يمكن اعادته لكن فقط يمكن قضاؤه بحكمة.

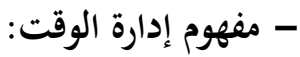

يرتبط مفهوم إدارة الوقت بالزمن الخاص المتاح للفرد بعد انتهاء مدة العمل الرسمي الذى يستطيع الفرد من خلاله ممارسة

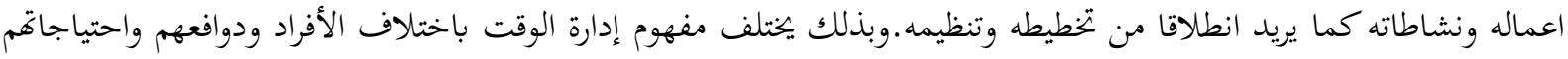

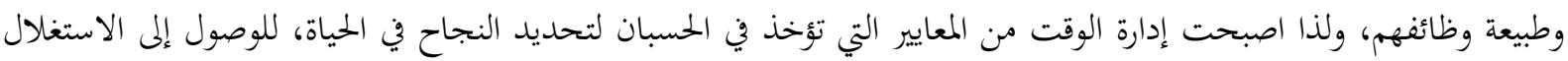

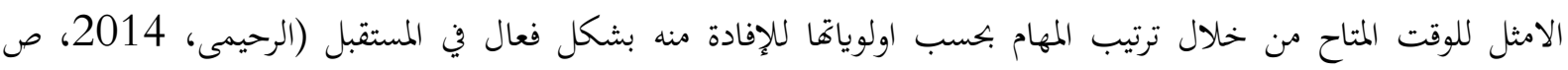

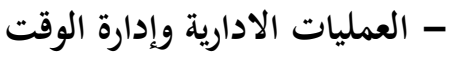

تتكون العمليات الإدارية من اربع وظائف وهي: التخطيط، والتنظيم، والتوجيه والرقابة. وفيما يلي توضيح لكل منها كما

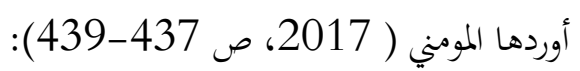

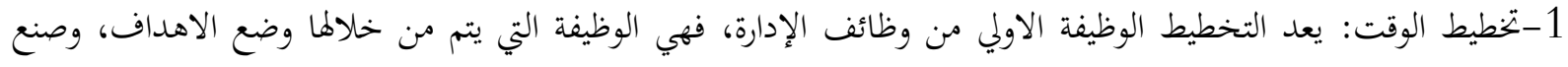

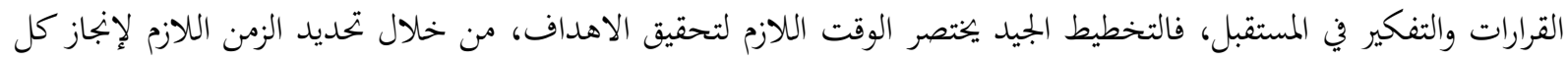

2- تنظيم الوقت: يعثل تنظيم الوقت الوسيلة التي عن طريقها يتم انجاز الأهداف، فالتنظيم ضرورة لابد منها لترتيب الجهود البشرية، وتصنيفها نت أجل الوصول إلى الغايات.

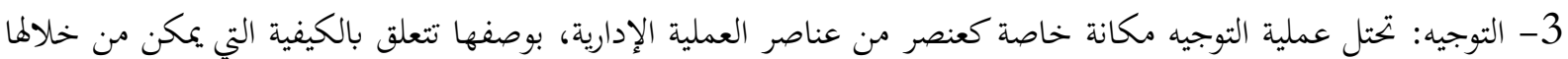

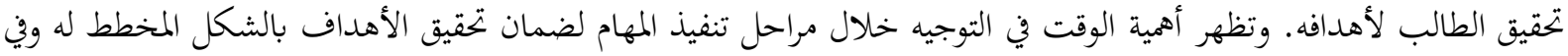

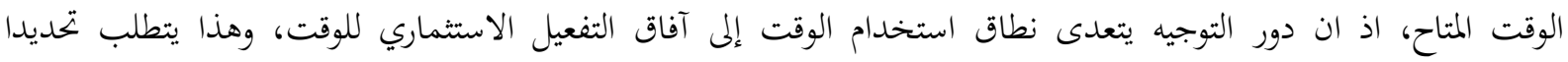

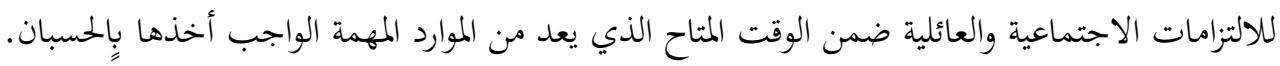

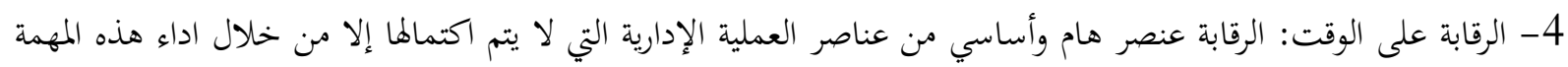
بشكل علمي وعملي، يؤدي إلى تحقيق مستوي كفؤ من الأداء.

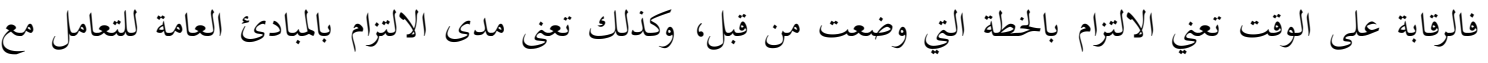

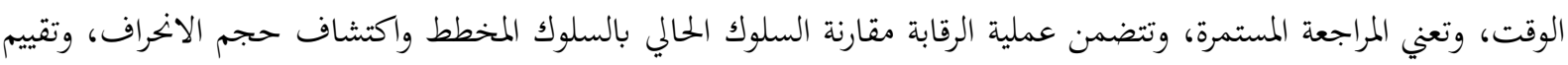

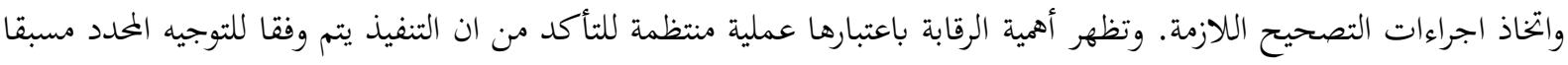

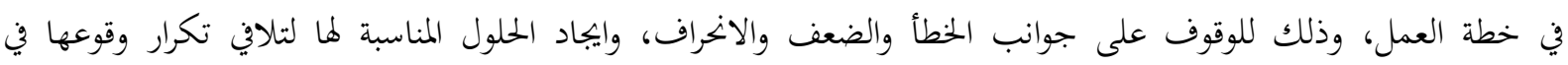


- معوقات تنظيم الوقت: تعرف معوقات تنظيم الوقت بأها نشاط غير ضروري يستغرق وقتا بطريقة غير ملائمة ولا يظهر منه

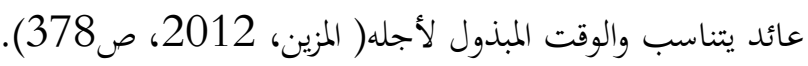

$$
\begin{aligned}
& \text { ومن أشكال هدر الوقت كما أوردها المزين ( 2012، ص378) كما يلي: }
\end{aligned}
$$

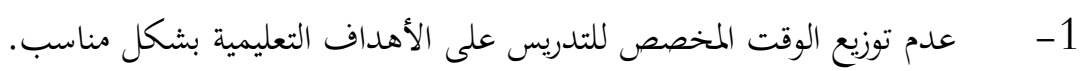

$$
\begin{aligned}
& \text { 2- - الوقت الضائع نتيجة كثافة الطلبة في تصحيح الكراسات وغيرها. } \\
& \text { 3- - الوقت الانتقالي بين القاعات الدراسية وايضا عند التحول من نشاط تعليم إلى نشاط تعليمي آخر. }
\end{aligned}
$$

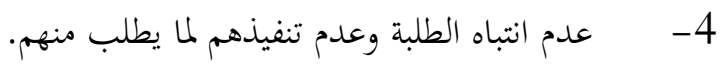

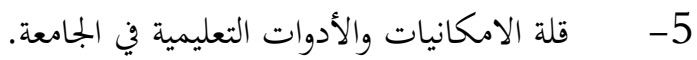

المبحث الثاني: التحصيل الدراسي

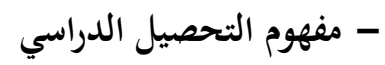

هو إتقان جملة من المهارات والمعارف التي يمكن أن يمتلكها الطالب بعد تعرضه لمجموعة من الخبرات التربوية في مادة

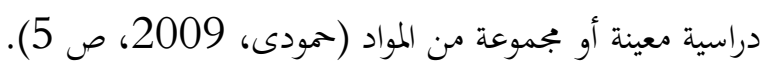

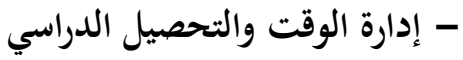

أشارت خلفان (2011، ص62) ان اختلاف الطلاب في تنظيمهم للزمن المتاح على المواد الدراسية والأنشطة الإدارية والفنية المختلفة، سوف يترتب عليه تفاوت التحصيل العلمي للطلاب واختلافهم في خبراتم بالمنهج التعليمي. وأوضحت بأنه من

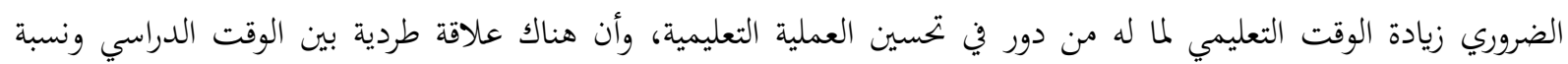
الحضور، وأن هناك علاقة عكسية بين الوقت المدرسي ونسبة التسرب.

\section{المبحث الثالث: امعة الزعيم الأزهري \\ - نبذة تاريخية:}

التعليم الأساسي:يقصد بالتعليم الأساسي القدر الضروري للتعليم والمعارف والقدرات الذهنية والقيم والمهارات الأساسية

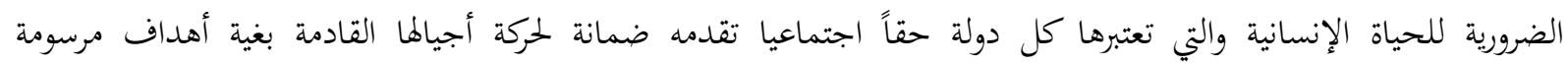

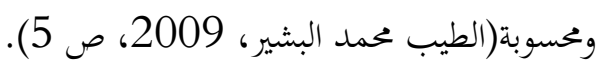

ويتبلور الطموح للنهضة في الوطن العربي في بجال بناء رأس المال البشري راقي النوعية، في غايات ثلاث (المؤتمر العالمي بجنيف، 2008، ص 36-37) وهي:

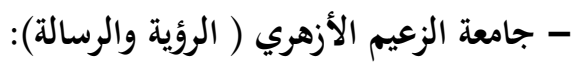
إن جامعة الزعيم الأزهري برؤيتها التي تتمثل في الريادة العلمية تميزا وانتماء ا لدعم مقومات النهضة القومية والانفتاح عالميا

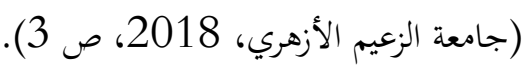

وأما رسالة جامعة الزعيم الأزهري تتمثل في تعزيز التحول لمجتمع المعرفة وقيم التعاون والتعاضد العلمي بكادي مادر مبدع وخريج

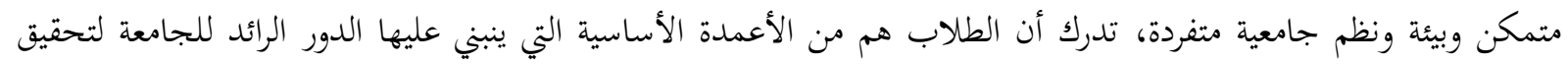

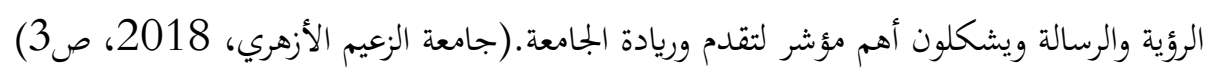




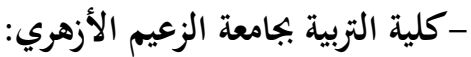

هي واحدة من كليات جامعة الزعيم الأزهري، انشئت عام 1993، وبدأت في استقبال أول دفعة من الطلاب عام

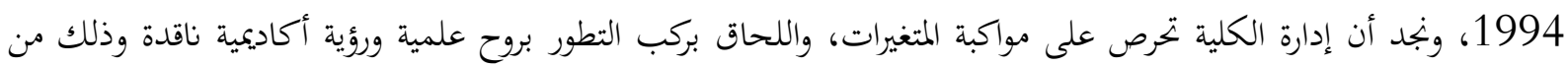

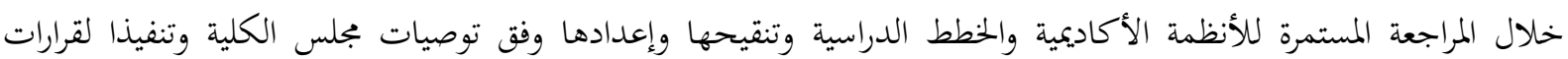

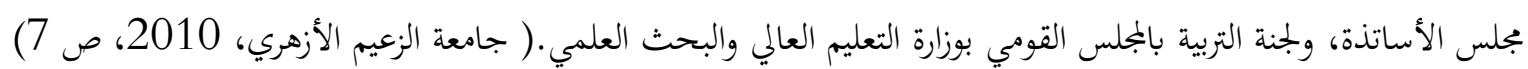
- الدراسات السابقة فيما يتعلق بالدراسات السابقة، لم بحد الباحثة الكثير من الدراسات المحلية، لذلك سوف نستعرض الدراسات العربية

عنوان الدراسة:إدارة الوقت وعلاقته بالدافعية للإنجاز والتحصيل لدى طلاب كلية الاقتصاد المنزلي، حيث بينت النتائج تفوق الطلاب على الطالبات في إدارة الوقت، كما بينت الدراسة تفوق طلاب السنة الثانية على طلاب السنة الأولى الذين درسوا

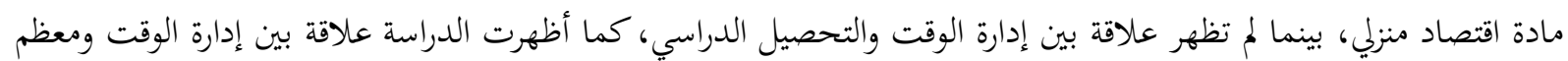
أبعاد دافعية الانجاز وهي: المثابرة، قلق التحصيل، المنافسة، التحكم في البيئة، احترام الذات والتوجه نهو المهيل المستقبل. 2-2005 2005):

بعنوان: مستويات إدارة الوقت لدى طالبات جامعة قطر وتخصهن الجامعي في علاقتها بالتحصيل الأكاديمي والرضا عن الحياة، حيث تكونت عينة الدراسة من (759) طالبة من كليات (التربية، الانسانيات، العلوم، الشريعة والاقتصاد) وقد بينت الدراسة عدم وجود فروق دالة احصائيا بين التخصص الأكاديمي ومستويات إدارة الوقت، كما بينت وجود فروق دالة الة احصائيا بين

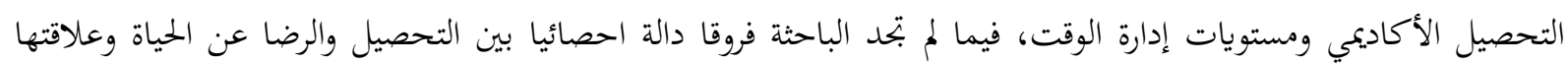
بمستويات إدارة الوقت. 3- 3 دراسة عبد العال (2009):

عنوان الدراسة:فاعلية إدارة الوقت لدى طلاب كلية المعلمين بحائل بالمملكة العربية السعودية وعلاقته بالتحصيل، هدفت

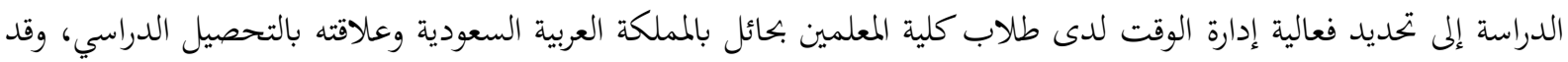

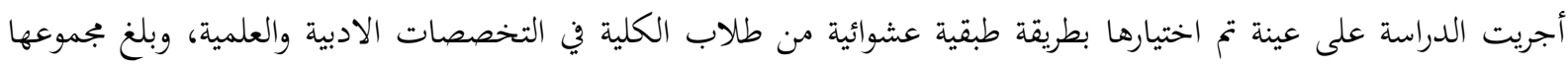

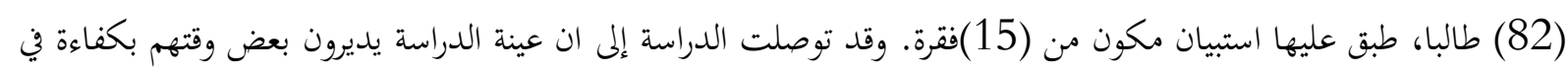

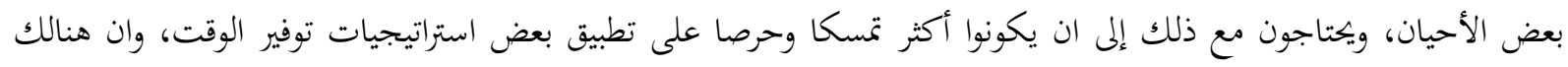
علاقة ارتباطية بين إدارة الوقت وبين التحصيل الدراسي، فكلما ارتفعت فعالية إدارة الوقت ارتفع معها التحصيل الدراسي. بعضي.

ثانيا: الدراسات الأجنبية

1- 1 دراسة اوغلو وفيلز (2008)

عنوان الدراسة:العلاقة بين إدارة الوقت والتحصيل الأكاديمي للطلبة الذين يدرسون في كليات التربية في جامعة غازي تركيا. بينت الدراسة ان سلوك الطالب في مجال تخطيط الوقت كان على مستوي عال، وفي مجال مضيعات الوقت كان في ادني 
مستوياته، كما ان نجاح الطلبة كان فوق المعدل، كما أظهرت الدراسة ان هناك علاقة ايجابية ذات دلالة بين تخطيط الوقت ومضيعات الوقت بين التحصيل الأكاديمي للطلبة، وهناك علاقة متوسطة ذات معنى بين إدارة الوقت والتحصيل الأكاديمي. كما

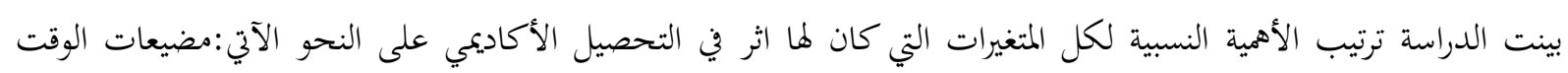
وتخطيط الوقت، والابحاه نحو الوقت.

2-2012 دراسة دانلنجر (2012)

عنوان الدراسة: اثر إدارة الوقت في التحصيل لدي الطلاب الجامعيين -الولايات المتحدة الامريكية، هدفت الدراسة

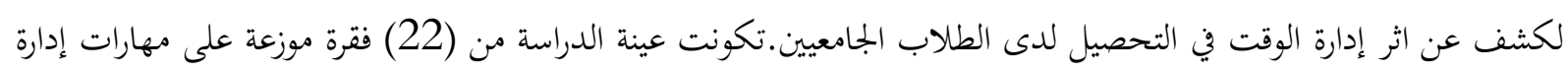
الوقت، وتنظيم الذات، وتم الحصول على علامات الطلاب من سجلاتم والحصول على تقارير اشراكهم في النشاطات

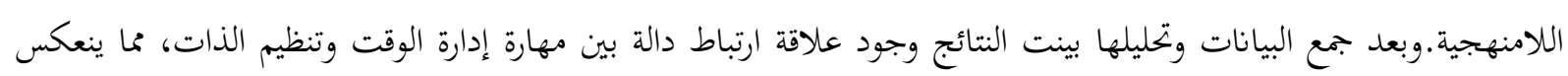

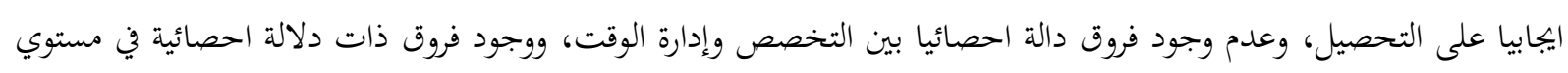

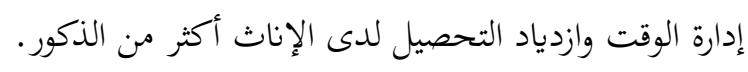

$$
\text { 3- دراسة دالي (2014) - دولة تركيا }
$$

عنوان الدراسة: مهارات إدارة الوقت لدى الطلبة الجامعيين على مستوى تحصيلهم الأكاديمي ورضاهم عن الحياة، هدفت

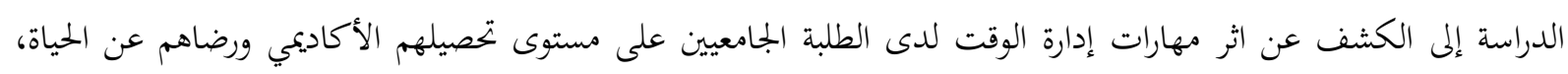

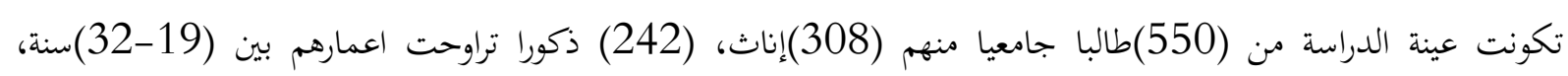

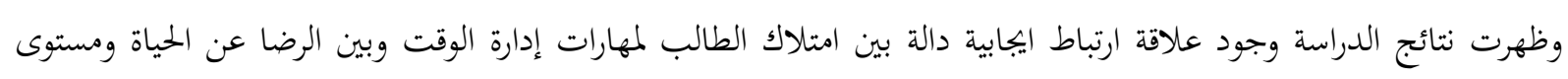

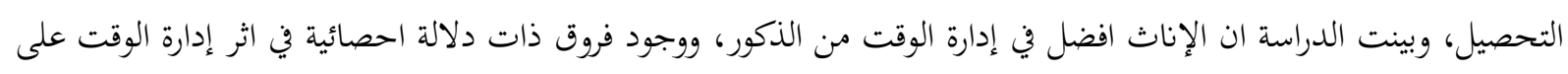
التحصيل والرضا عن الحياة لمن تزيد اعمارهم عن (26) سنة.

\section{التعليق على الدراسات السابقة:}

من خلال الدراسات السابقة لاحظت الباحثة أن معظم الدراسات تمثلت أهدافها في الكشف عن العلاقة بين إدارة

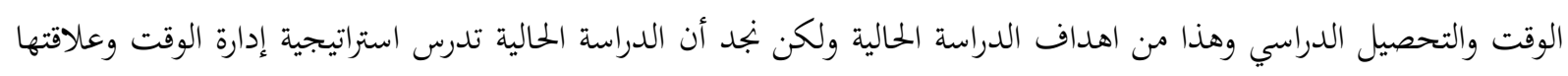

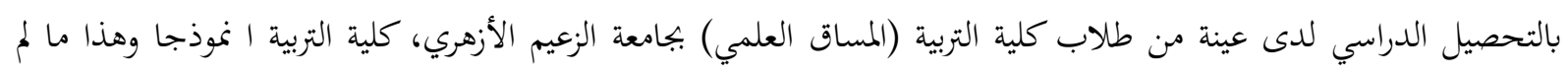

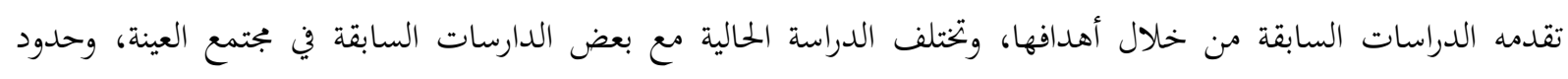
الدارسة والمنهج المستخدم، وقد استفادت الباحثة من الدارسات السابقة في إعداد الخطة، والاستبانة وفي كتابة الإطار النظري. 


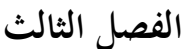

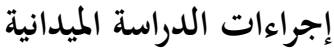

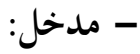

يشتمل هذا الفصل إجراءات الدراسة الميدانية التي أتبعتها الباحثة حيث تتناول المنهج وبجتمع الدراسة وعينتها وأداة

الدراسة و المعالجات الإحصائية.

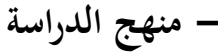

أتبعت الباحثة المنهج الوصفي التحليلي الذي يناسب هذا النوع من الدراسات، حيث قدف البحوث الوصفية إلى وصف ظواهر أو أحداث أو أشياء معينة وجمع الحقائق والمعلومات والملاحظات عنها ووصف الظروف الخاصة بها وتقرير حالتها كما

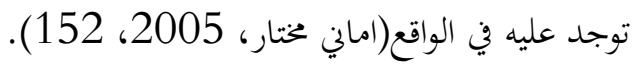

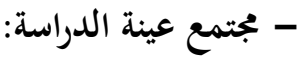

يتكون مجتمع الدراسة من طلاب المساق العلمي بكلية التربية بجامعة الزعيم الأزهري البالغ عددهم (572) طالب وطالبة، اما عينة الدراسة بلغ عددها (94) من طلاب المساق العلمي بكلية التربية بجامعة الزعيم الأزهري.

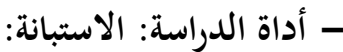

القسم الأول البيانات الشخصية للمفحوصين وقد كانت ( الجنس، التخصص، المعدل التراكمي، السكن)

$$
\text { القسم الثاني: محاور الاستبانة. }
$$

اختارت الباحثة الاستبانة المقيدة كوسيلة لجمع المعلومات من عينة الدراسة وهو نوع يسمح باختيار الإجابات المناسبة من

$$
\text { بين بدائل، مقياس لكرت الثلاثي. }
$$

\section{- - الخصائص السيكو مترية للمقياس:}

صدق الاتساق الداخلي مع الدرجة الكلية:: (Internal Validity):

قامت الباحثة بحساب معاملات ارتباط (بيرسون) Pearson correlation بين درجات كل بند من بنود الاستبانة والدرجة الكلية لمجموع الاستبانة الكلية، واتضح من هذا الإجراء أن جميع بنود الاستبانة لها معامل ارتباط موجب غير صفري بالدرجة الكلية، ما عدا البند رقم (8)والجدول التالي يوضح ذلك.

\begin{tabular}{|c|c|c|c|c|c|}
\hline معامل الارتباط & رقم & معامل الارتباط & رقم & معامل الارتباط & رقم \\
\hline 0.448 & 25 & 0.214 & 13 & 0.450 & 1 \\
\hline 0.525 & 26 & 0.471 & 14 & 0.402 & 2 \\
\hline 0.413 & 27 & 0.411 & 15 & 0.400 & 3 \\
\hline 0.273 & 28 & 0.256 & 16 & 0.573 & 4 \\
\hline 0.546 & 29 & 0.206 & 17 & 0.576 & 5 \\
\hline 0.353 & 30 & 0.344 & 18 & 0.125 & 6 \\
\hline 0.335 & 31 & 0.325 & 19 & 0.536 & 7 \\
\hline
\end{tabular}

جدول رقم (1) يوضح معامل ارتباط بيرسون بين درجة كل عبارة والدرجة الكلية لمحاور الاستبانة 


\begin{tabular}{|r|r|r|r|r|r|}
\hline 0.485 & 32 & 0.107 & 20 & 0.087 & 8 \\
\hline 0.223 & 33 & 0.257 & 21 & 0.235 & 9 \\
\hline 0.301 & 34 & 0.252 & 22 & 0456 & 10 \\
\hline 0.331 & 35 & 0.192 & 23 & 0.368 & 11 \\
\cline { 3 - 6 } & & 0.319 & 24 & 0.271 & 12 \\
\hline
\end{tabular}

يتضح من الجلدول السابق ان جميع بنود استبانة استراتيجية إدارة الوقت لدى طلاب كلية التربية بجامعة الزعيم الأزهري موجبة غير

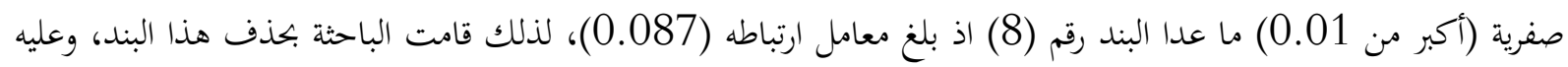

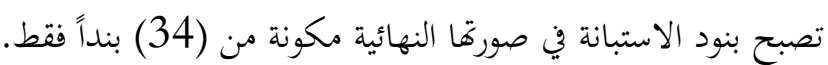
معامل الثبات:جدول رقم (2) يوضح معامل الثبات بطريقة الفاكروبناك والتجزئة النصفية لكل محور من محاور الاستبانة والاستبانة

\begin{tabular}{|c|c|c|c|c|}
\hline \multicolumn{2}{|r|}{ التجزئة النصفية } & معامل & عدد البنود & لمحور \\
\hline سبيرمان- & الارتباط بين & الفاكروبناك & & \\
\hline 0.612 & 0.441 & 0.707 & 9 & لتخطيط \\
\hline 0.510 & 0.342 & 0.623 & 10 & لتنظيم \\
\hline 0.618 & 0.447 & 0.510 & 5 & لتوجيه \\
\hline 0.633 & 0.463 & 0.660 & 5 & لتقويم \\
\hline 0502 & 0.329 & 0.566 & 5 & مضيعات الوقت \\
\hline 0.648 & 0.479 & 0.747 & 34 & لاستبانة الكلية \\
\hline
\end{tabular}

توصيف عينة الدراسة:

\begin{tabular}{|c|c|c|}
\hline النسبة المئوية ( \%) & التكرار & | الجنس \\
\hline$\% 28$ & 26 & ذكر \\
\hline$\% 72$ & 67 & أنثى \\
\hline$\% 100$ & 93 & المجموع \\
\hline
\end{tabular}

يتضح من الجدول أعلاه بأن عدد الإناث أكثر من الذكور حوالي 72 \% بينما الذكور يبلغ عددهم حوإلى 28\% من النسبة

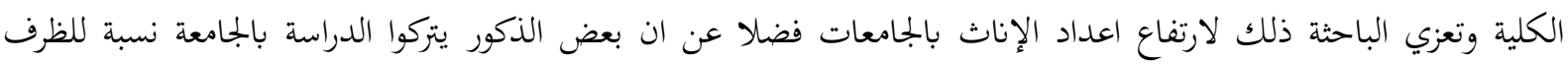
الاقتصادية والاجتماعية الضاغطة. 
جدول رقم ( 4) يوضح توزيع أفراد عينة الدراسة وفقا للتخصص الأكاديمي

\begin{tabular}{|c|c|c|}
\hline النسبة المئوية ( \%) & التكرار & المؤهل الأكاديمي \\
\hline$\% 15.1$ & 14 & فيزياء \\
\hline$\% 32.2$ & 30 & رياضيات \\
\hline$\% 23.7$ & 22 & كيمياء \\
\hline$\% 29$ & 27 & احياء \\
\hline$\% 100$ & 93 & المجموع \\
\hline
\end{tabular}

يتضح من الجدول أعلاه بأن طلاب قسم الرياضيات هم يشكلون اعلى نسبة حوالي 32.2\% من جملة طلاب أفراد عينة الدراسة

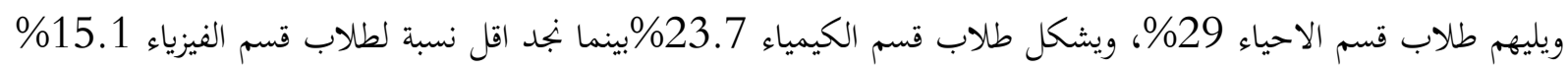
ويعزى ضعف هذه النسبة لرغبة الطلاب في تخصص في المواد التي يحتاجها سوق وقلئ العمل. جدول رقم (5) يوضح توزيع أفراد عينة الدراسة وفقا للمعدل التراكمي.

\begin{tabular}{|c|c|c|}
\hline النسبة المئوية ( \%) & التكرار & المعدل التراكمي \\
\hline$\% 9.7$ & 9 & من 22إلى اقل من 2.5 \\
\hline$\% 47.3$ & 44 & من 2.5إلى اقل من 3 \\
\hline$\% 43$ & 40 & 3 فأكثر \\
\hline$\% 100$ & 93 & المجموع \\
\hline
\end{tabular}

يتضح من الجدول اعلاه بأن حوالي 90.3\% من الطلاب معدلمم التراكمي يتراوح بين 2.5\%- وأكثر من 3\%ة \% بينما بلغت

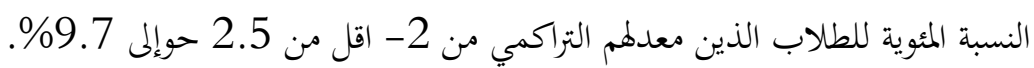
جدول رقم (6) يوضح توزيع أفراد عينة الدراسة وفقا للسكن

\begin{tabular}{|c|c|c|}
\hline النسبة المئوية ( \%) & التكرار & السكن \\
\hline$\% 35.5$ & 33 & دخلي \\
\hline$\% 64.5$ & 60 & خارجي \\
\hline$\% 100$ & 93 & المجموع \\
\hline
\end{tabular}

من الجدول أعلاه يتضح بأن معظم أفراد العينة 64.5 يسكنون سكنا خارجيا ويعزى ذلك لعدم توفر اماكن شاغرة بالنسبة ومعظمهم يأتي من خارج ولاية الخرطوم فيضطر بعضهم للسكن مع اقاركمم في أغلب الأحيان. 
الفصل الرابع (تحليل البيانات ومناقشة النتائج)

عرض ومناقشة نتيجة الفرض الأول: عرض نتيجة الفرض الأول:

للتحقق من صحة نتيجة الفرض الأول والذي ينص على انه ( توجد فروق ذات دلالة إحصائية في أبعاد استراتيجية إدارة

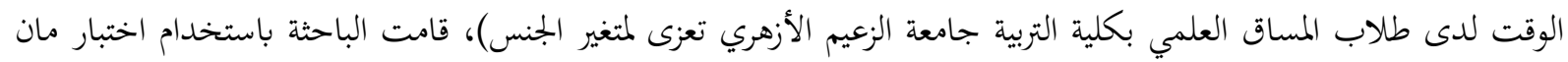
- وتني ( Mann- Whitney)، وأظهرت نتائج التحليل الاحصائي الجدول التالي.

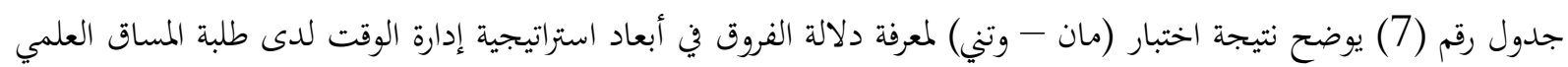
بكلية التربية جامعة الزعيم الأزهري والتي تعزى لمتغير الجنس.

\begin{tabular}{|c|c|c|c|c|c|c|c|}
\hline الاحتمالية & قلميمة (z) & قيمة المعلمة (u) & مجموع الرتب & متوسط & $\tau^{2}$ & المقارنة & أبعاد إستبانة إستبة الوقتية \\
\hline \multirow[t]{2}{*}{0.777} & \multirow[t]{2}{*}{0.284} & \multirow[t]{2}{*}{838.000} & 3182.00 & 47.49 & 67 & الإناث & \multirow[t]{2}{*}{ التخطيط } \\
\hline & & & 1189.00 & 45.73 & 26 & الذكور & \\
\hline \multirow[t]{2}{*}{0.012} & \multirow[t]{2}{*}{2.508} & \multirow[t]{2}{*}{579.500} & 3440.50 & 51.35 & 67 & الإناث & \multirow[t]{2}{*}{ التنظيم } \\
\hline & & & 930.50 & 35.79 & 26 & الذكور & \\
\hline \multirow[t]{2}{*}{0.009} & \multirow{2}{*}{2.598} & \multirow{2}{*}{571.000} & 3449.00 & 51.48 & 67 & الإناث & \multirow[t]{2}{*}{ التوجيه } \\
\hline & & & 922.00 & 35.46 & 26 & الذكور & \\
\hline \multirow[t]{2}{*}{0.204} & \multirow[t]{2}{*}{1.271} & \multirow[t]{2}{*}{724.500} & 3295.50 & 49.19 & 67 & الإناث & \multirow[t]{2}{*}{ التقويم } \\
\hline & & & 1075.50 & 41.37 & 26 & الذكور & \\
\hline \multirow[t]{2}{*}{0.005} & \multirow[t]{2}{*}{2.785} & \multirow[t]{2}{*}{550.000} & 2828.00 & 42.21 & 67 & الإناث & \multirow{2}{*}{ مضيعات } \\
\hline & & & 1543.00 & 59.35 & 26 & الذكور & \\
\hline \multirow[t]{2}{*}{0.108} & \multirow[t]{2}{*}{1.607} & \multirow[t]{2}{*}{683.500} & 3336.50 & 49.80 & 67 & الإناث & \multirow{2}{*}{ اللارجة اللية } \\
\hline & & & 1034.50 & 39.79 & 26 & الذكور & \\
\hline
\end{tabular}

من الجدول اعلاه يلاحظ في أبعاد استراتيجية إدارة الوقت لدى طلبة المساق العلمي بكلية التربية جامعة الزعيم الأزهري والتي تعزى لمتغير الجنس، كانت النتائج كالتالي: 1

بالنظر إلى الجدول أعلاه يلاحظ ان قيمة المعلمة (u) بلغت

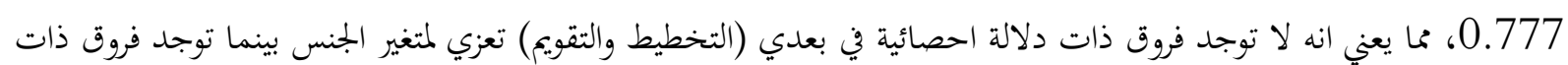
دلالة احصائية لبقية الأبعاد (التنظي، التوجيه، مضيعات الوقت) تعزى لمتغير الجنس. 2- 2حور التنظيم

بالنظر إلى الجدول أعلاه يلاحظ ان قيمة المعلمة (u) بلغت 0.012، مما يعني انه لا توجد فروق ذات دلالة احصائية في بعد التنظيم تعزي لمتغير الجنس. بينما توجد فروق ذات دلالة

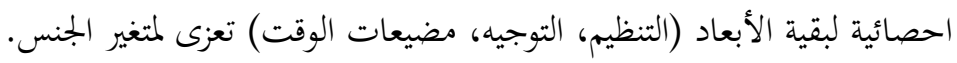




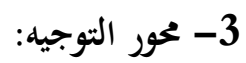

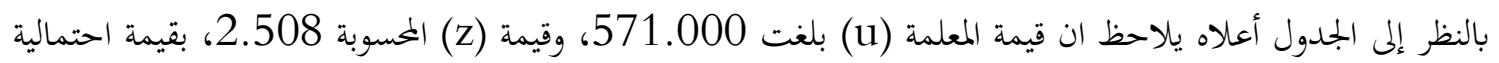
0.009، مما يعني انه توجد فروق ذات دلالة احصائية في بعد التنظيم تعزي لمتغير الجنس. 4- محور التقويم:

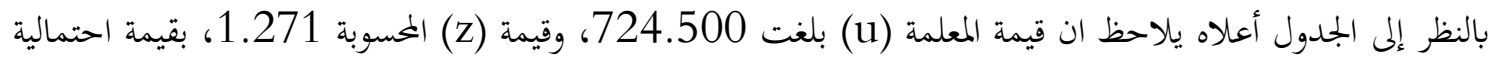
0.204، مما يعني انه لا توجد فروق ذات دلالة احصائية في بعد التقويم تعزي لمتغير الجنس.

5-مضيعات الوقت:

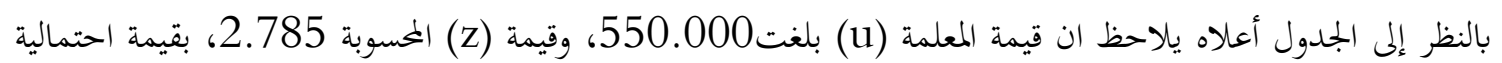

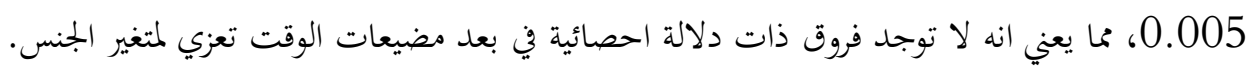

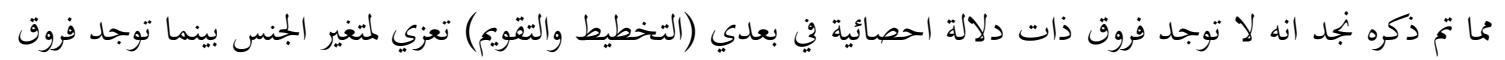
ذات دلالة احصائية لبقية الأبعاد (التنظيم، التوجيه، مضيعات الوقت) تعزى لمتغير الجنس، إلا أن الدرجة الكلية(السمة العامة)

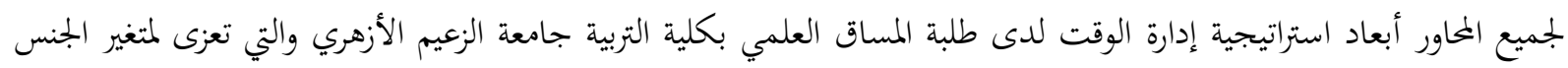

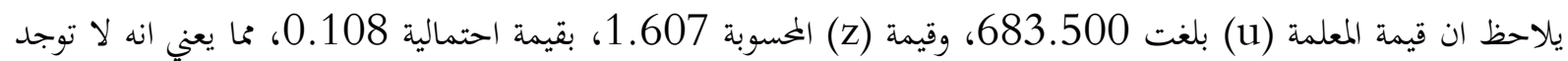
فروق ذات دلالة احصائية في تعزي لمتغير الجنس. عرض نتيجة الفرض الثاني: للتحقق من صحة نتيجة الفرض الثاني والذي ينص على انه ( توجد فروق ذات دلالة إحصائية في أبعاد استراتيجية إدارة

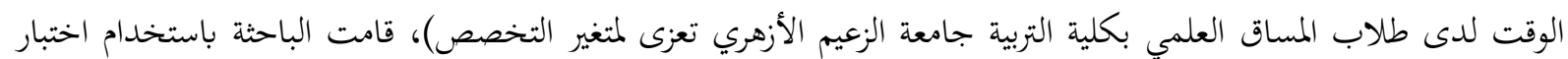
تحليل التباين الأحادي (ANOVA)، وأظهرت نتائج التحليل الاحصائي الجدول التالي. جدول رقم (8) يوضح نتيجة اختبار تحليل التباين الأحادي (ANOVA) لمعرفة دلالة الفروق في أبعاد استراتيجية إدارة الوقت لدى طلبة المساق العلمي بكلية التربية جامعة الزعيم الأزهري والتي تعزى لمتغير التخصص. جدول رقم (8) يوضح نتيجة اختبار تحليل التباين الأحادي (ANOVA) لمعرفة دلالة الفروق في أبعاد استراتيجية إدارة

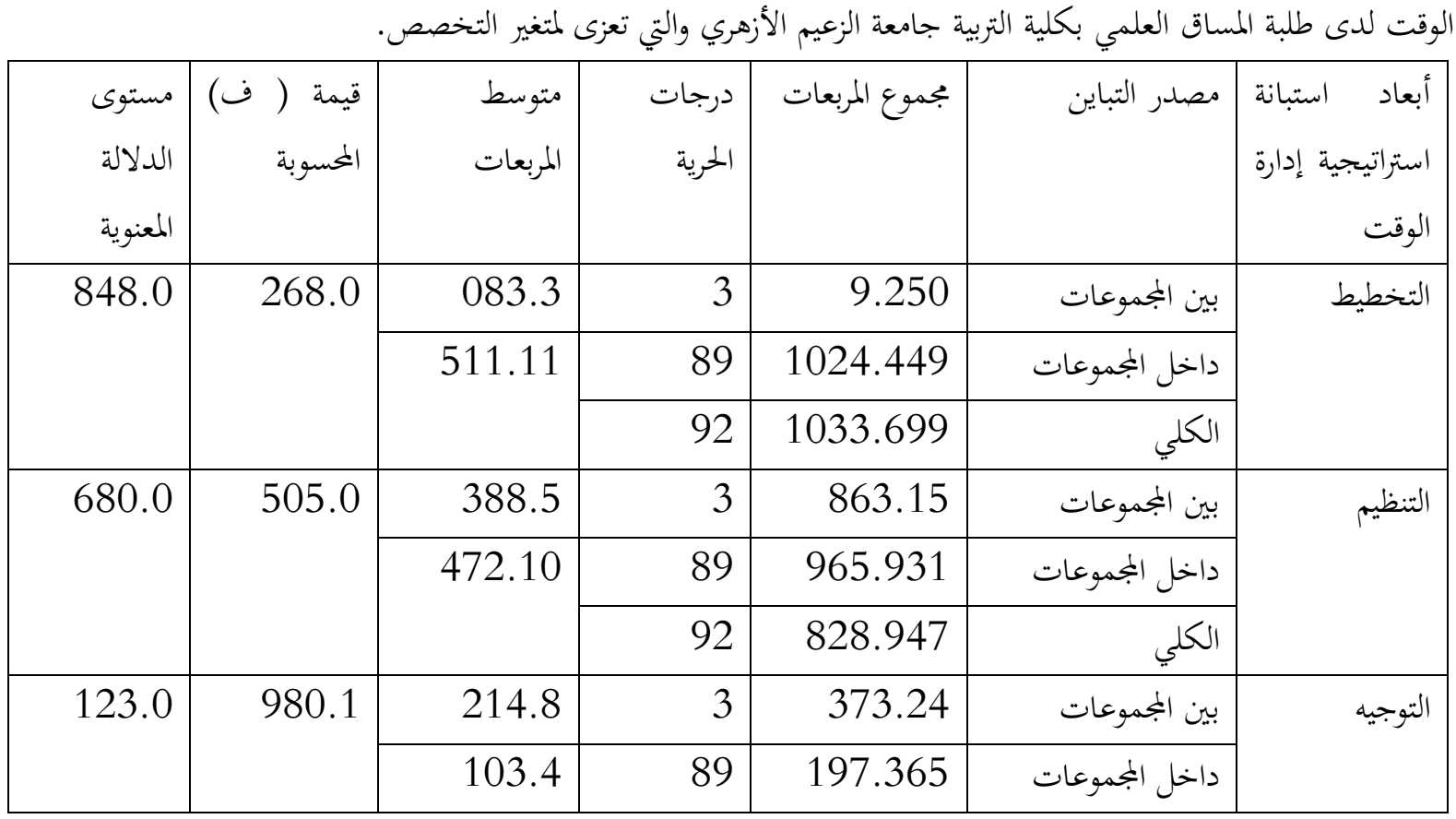




\begin{tabular}{|c|c|c|c|c|c|c|}
\hline & & & 92 & 570.389 & الكلي & \\
\hline \multirow[t]{3}{*}{434.0} & \multirow[t]{3}{*}{922.0} & 368.4 & 3 & 104.13 & بين المجموعات & \multirow{3}{*}{ التقويم } \\
\hline & & \multirow[t]{2}{*}{737.4} & 89 & 563.421 & داخل المجموعات & \\
\hline & & & 92 & 667.443 & الكلي & \\
\hline \multirow[t]{3}{*}{052.0} & \multirow{3}{*}{2678.0} & 678.10 & 3 & 034.32 & بين المجموعات & \multirow{3}{*}{ مضيعات } \\
\hline & & \multirow[t]{2}{*}{988.3} & 89 & 891.354 & داخل المجموعات & \\
\hline & & & 92 & 925.386 & الملي & \\
\hline \multirow[t]{3}{*}{369.0} & \multirow[t]{3}{*}{063.1} & 936.62 & 3 & 010.188 & بين المجموعات & \multirow{3}{*}{ للاستبانة الدرجة الكلية } \\
\hline & & \multirow[t]{2}{*}{936.58} & 89 & 034.5345 & داخل المجموعات & \\
\hline & & & 92 & 034.5433 & الكلي & \\
\hline
\end{tabular}

في أبعاد استراتيجية إدارة الوقت لدى طلبة المساق العلمي بكلية التربية جامعة الزعيم الأزهري والتي تعزى لمتغير التخصص،

كانت النتائج كالتالي:

1

بالنظر إلى الجدول أعلاه يلاحظ أن قيمة (ف) المحسوبة بلغت 268.0، بقيمة احتمالية، 848.0 مالما يعني عدم وجود فروق دالة احصائيا عند مستوى دلالة معنوية 0.05، في محور التخطيط لدى تعزى لمتغير التخصص.

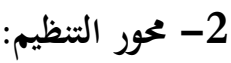

بالنظر إلى الجدول أعلاه يلاحظ أن قيمة (ف) المحسوبة بلغت 505.0، بقيمة احتمالية، 680.0 مالما يعني عدم وجود فروق دالة احصائيا عند مستوى دلالة معنوية 0.05، في محور التنظيم لدى تعزى لمتغير التخصص. 3- محور التوجيه: بالنظر إلى الجدول أعلاه يلاحظ أن قيمة (ف) المحسوبة بلغت 980.1، بقيمة احتمالية، 123.0 مما يعني عدم وجود فروق دالة احصائيا عند مستوى دلالة معنوية 0.05، في محور التوجيه لدى تعزى لمتغير التخصص.

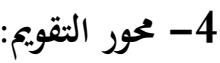

بالنظر إلى الجدول أعلاه يلاحظ أن قيمة (ف) المحسوبة بلغت 922.0، بقيمة احتمالية، 434.0 مما يعني عدم وجود

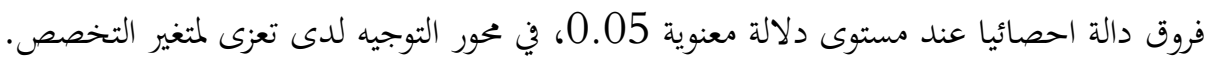
5 - 5حور مضيعات الوقت:

بالنظر إلى الجدول أعلاه يلاحظ أن قيمة (ف) المحسوبة بلغت 2678.0، بقيمة احتمالية،

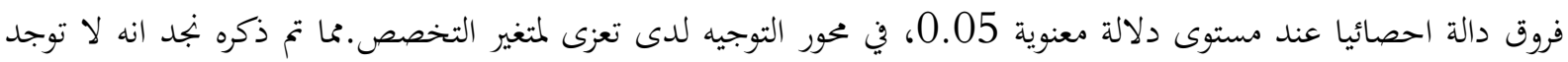
فروق ذات دلالة احصائية تعزي لمتغير التخصص، إلا أن الدرجة الكلية(لجميع المحاور) أبعاد استراتيجية إدارة الوقت لدى طلبية المساق العلمي بكلية التربية جامعة الزعيم الأزهري والتي تعزى لمتغير التخصص يلاحظ ان قيمة(ف)الخسوبة بلغت

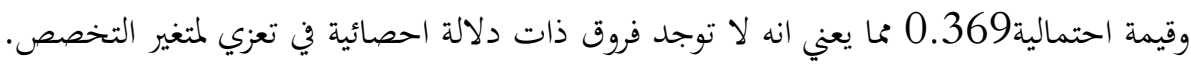




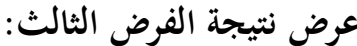

للتحقق من صحة نتيجة الفرض الثالث والذي ينص على انه ( توجد فروق ذات دلالة إحصائية في أبعاد استراتيجية

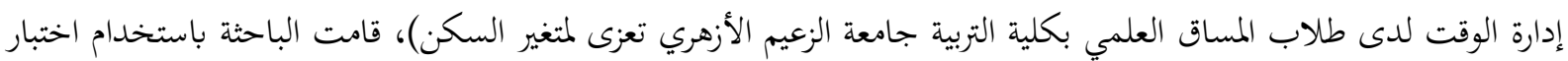
(ت) لمتوسط مجموعتين مستقلتين (، وأظهرت نتائج التحليل الاحصائي الجدول التالي.

جدول رقم (9) يوضح نتيجة اختبار (ت) لمتوسط مجموعتين مستقلتين لمعرفة دلالة الفروق في أبعاد استراتيجية إدارة الوقت لدى

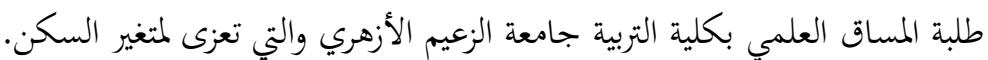

\begin{tabular}{|c|c|c|c|c|c|c|}
\hline مستوى الدلالة & المحسوبة $\quad$ (ت) & درجات الحرية & الانحراف & |الوسطابي & مجموعتا المقارنة & أبعاد إستراتيجة البتبانة \\
\hline \multirow[t]{2}{*}{0.277} & \multirow[t]{2}{*}{1.094} & \multirow[t]{2}{*}{91} & 3.23335 & 20.2727 & داخلي & \multirow[t]{2}{*}{ التخطيط } \\
\hline & & & 3.40919 & 21.0667 & خارجي & \\
\hline \multirow[t]{2}{*}{0.708} & \multirow[t]{2}{*}{0.375} & \multirow[t]{2}{*}{91} & 3.51566 & 23.2121 & داخلي & \multirow[t]{2}{*}{ التنظيم } \\
\hline & & & 3.0556 & 22.9500 & خارجي & \\
\hline \multirow[t]{2}{*}{0.759} & \multirow[t]{2}{*}{0.308} & \multirow[t]{2}{*}{91} & 2.01697 & 11.5455 & داخلي & \multirow[t]{2}{*}{ التوجيه } \\
\hline & & & 2.09512 & 11.6833 & خارجي & \\
\hline \multirow[t]{2}{*}{0.767} & \multirow[t]{2}{*}{0.298} & \multirow[t]{2}{*}{91} & 2.00047 & 11.2424 & داخلي & \multirow{2}{*}{ التقويم } \\
\hline & & & 2.27806 & 11.3833 & خارجي & \\
\hline \multirow[t]{2}{*}{0.879} & \multirow[t]{2}{*}{0.153} & \multirow[t]{2}{*}{91} & 2.06339 & 7.5152 & داخلي & \multirow{2}{*}{ مضيعات } \\
\hline & & & 2.06087 & 7.5833 & خارجي & \\
\hline \multirow[t]{2}{*}{0.600} & \multirow[t]{2}{*}{0.526} & \multirow[t]{2}{*}{91} & 7.70048 & 73.7879 & داخلي & \multirow{2}{*}{ للاستبانة الدرجة الكلية } \\
\hline & & & 7.72332 & 74.667 & خارجي & \\
\hline
\end{tabular}

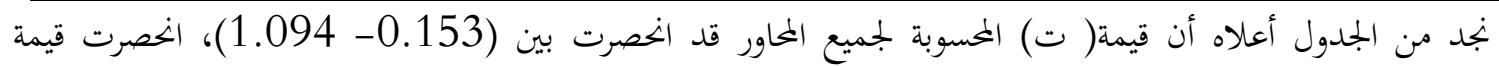

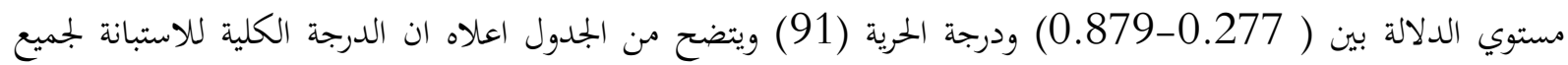
محاورها قيمة ت المحسوبة(0.526) وقيمة مستوى دلالة (0.600) مما يعني عدم وجود فروق دالة احصائيا عند مستوى دلالة معنوية 0.05، في محاور استبانة استراتيجية إدارة الوقت بأبعادها المختلفة ( التخطيط، التنظيم، التوجيه، التقويم ومضيعات الوقت) تعزى لمتغير السكن. عرض ننيجة الفرض الرابع:

للتحقق من صحة نتيجة الفرض الرابع والذي ينص على أنه ( توجد علاقة ارتباطية طردية " موجبة) بين أبعاد استراتيجية

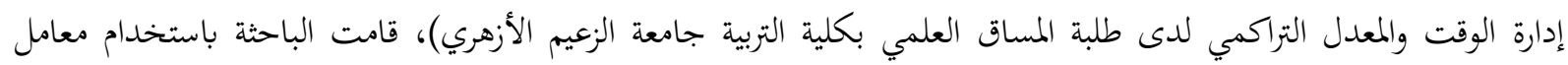
ارتباط بيرسون، وأظهرت نتائج التحليل الإحصائي جدول رقم (10) ما يأتي:

\begin{tabular}{|c|c|c|c|}
\hline مستوى الدلالة & درجات الحرية & قالتراكمة معامل ارتباط بيرسون مع المعدل & 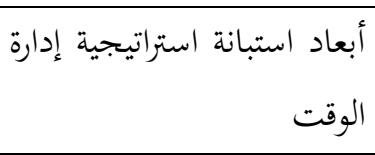 \\
\hline 0.01 & 93 & $0.418^{* * *}$ & التخطيط \\
\hline
\end{tabular}




\begin{tabular}{|c|c|c|c|}
\hline 0.05 & 93 & $0.209^{*}$ & التنظيم \\
\hline 0.05 & 93 & $0.248^{*}$ & التوجيه \\
\hline 0.05 & 93 & $0.265^{*}$ & التقويم \\
\hline
\end{tabular}

يتضح من الجدول اعلاه لا بعاد استراتيجية إدارة الوقت في بعد التخطيط قيمة معامل ارتباط بيرسون والمعدل التراكمي (01)

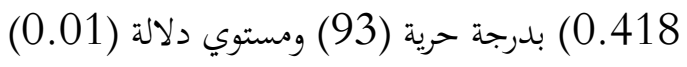

أما في بعد التنظيم قيمة معامل ارتباط بيرسون والمعدل التراكمي ( 0.209) بدرجة حرية (93) ومستوي دلالة (0.05))، وفي بعد التوجيه قيمة معامل ارتباط بيرسون والمعدل التراكمي (

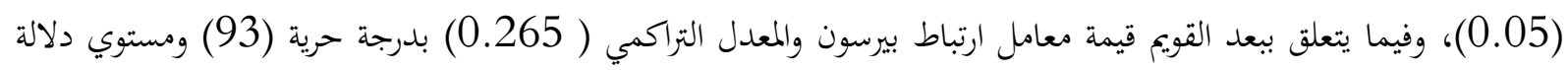

ومما سبق ذكره يتضح ان هنالك علاقة ارتباطية طردية موجبة بين أبعاد استراتيجية إدارة الوقت (التخطيط، التنظيم، التوجيه، التقويم) لدى طلبة المساق العلمي بكلية التربية بجامعة الزعيم الأزهري والمعدل التراكمي.

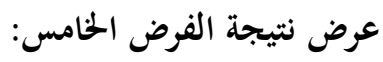

للتحقق من صحة نتيجة الفرض الخامس والذي ينص على أنه ( توجد علاقة ارتباطية عكسية " سلبية) بين مضيعات

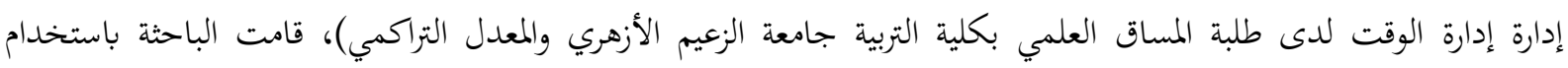
معامل ارتباط بيرسون، وأظهرت نتائج التحليل الإحصائي الجدول التالي. جدول رقم (11) يوضح نتيجة معامل الارتباط العزمي لبيرسون لمعرفة دلالة العلاقة الارتباطية بين مضيعات إدارة الوقت لدى

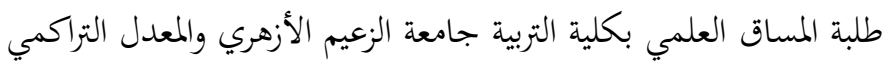

\begin{tabular}{|c|c|c|c|}
\hline مستوى الدلالة & درجات الحرية & قيمة معامل ارتباط بيرسون مع المعدل & 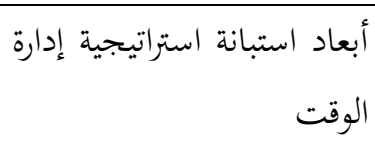 \\
\hline 0.01 & 93 & 0.499 ***_ & مضيعات إدارة الوقت \\
\hline
\end{tabular}

أظهر معامل ارتباط بيرسون وجود علاقة ارتباطية فيما بين المعدل التراكمي و مضيعات الوقت حيث بلغت قيمة معامل معامل

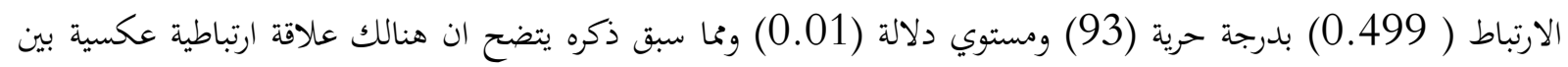

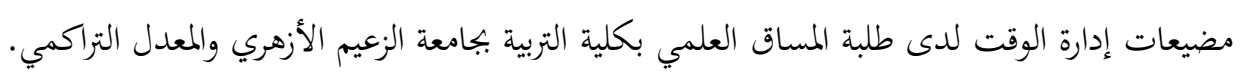
عرض نتيجة الفرض السادس: للتحقق من صحة نتيجة الرفض السادس والذي ينص على أنه ( توجد فروق ذات دلالة إحصائية في المعدل التراكمي لدى طلبة

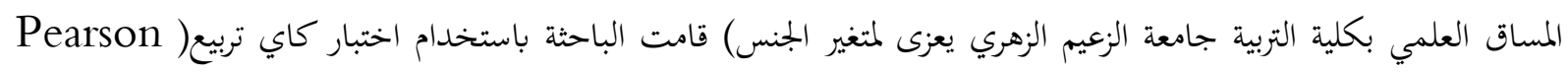
Chi- Square جدول رقم (12) يوضح نتيجة اختبار مربع كاي لمعرفة دلالة الفروق في المعدل التراكمي لدى طلبة المساق العلمي بكلية التربية جامعة الزعيم يعزى لمتغير الجنس.

\begin{tabular}{|c|c|c|c|c|c|c|}
\hline \multirow[t]{2}{*}{ مستوى الدلالة } & \multirow[t]{2}{*}{ درجة الحرية } & \multirow{2}{*}{ كاي } & \multicolumn{3}{|c|}{ الجنس } & \multirow[t]{2}{*}{ المعدل التراكمي } \\
\hline & & & المجموع & انتى & ذكر & \\
\hline 0.043 & 93 & 4.208 & 9 & 5 & 4 & 2 وأقل من 2.5 \\
\hline
\end{tabular}


Rimak International Journal of Humanities and Social Sciences

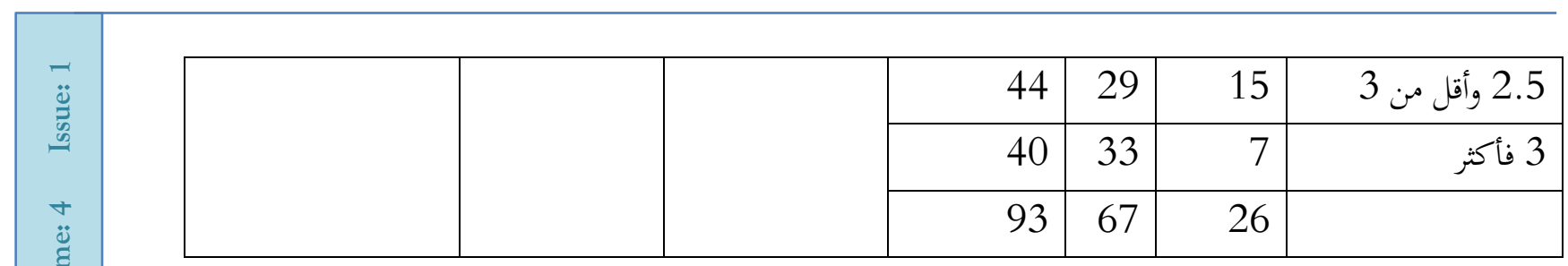

نلاحظ من الجدول أعلاه ان قيمة كا2 المحسوبة المقدرة (4.208)، بدرجة حرية (93)عند مستوى دلالة (0.043)

توضح بان هنالك فروق ذات دلالة احصائية في المعدل التراكمي لدي طلبة المساق العلمي بكلية التربية تعزى لمتغير الجنس. 


\section{الفصل الخامس \\ النتائج والثوصيات}

استناداً على نتائج تحليل البيانات في الفصل السابق تعرض الباحثة أهم النتائج التي توصلت إليها الدراسة، والتي على

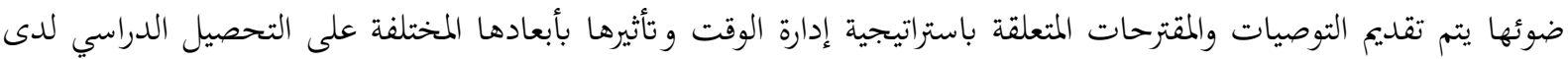
طلاب كلية التربية بجامعة الزعيم الأزهري. وتتلخص أهم النتائج في هذه الدراسة فيما يلي: 1- لا توجد فروق ذات دلالة احصائية لدى طلاب بكلية التربية تعزي لمتغير الجنس. 2- لا توجد فروق ذات دلالة احصائية لدى طلاب كلية التربية تعزى لمتغير السكن.

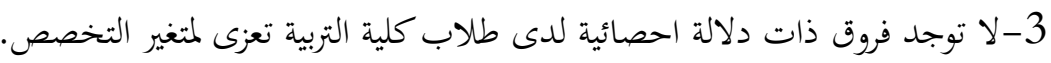

4- توجدعلاقة ارتباطية طردية موجبة بين أبعاد استراتيجية إدارة الوقت (التخطيط، التنظيم، التوجيه، التقويم) والمعدل التراكمي لتولئي

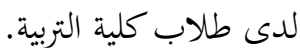

5- توجد علاقة ارتباطية عكسية سلبية بين مضيعات إدارة الوقت لدى طلاب المساق العلمي بكلية التربية والمعدل التراكمي. 6- فروق ذات دلالة احصائية في المعدل التراكمي لدي طلبة المساق العلمي بكلية التربية تعزى لمتغير الجنس. من خلال ما توصلت إليه الباحثة من نتائج قد أوصت بما يأتي: 1-ضرورة عقد ورش تدريبية للطلاب حول أهمية الوقت في حياة الطالب الأكاديمية والاجتماعية بجامعة الزعيم الأزهري. 2-ادخال مقرر دراسي بجميع مراحل التعليم العام والعالي يختص بإدارة الوقت واستراتيجياته.

3- تطوير مهارات استثمار الوقت، لزيادة التحصيل الدراسي لدى طلاب المساق العلمي بكلية التربية بجامعة الزعيم الأزهري.

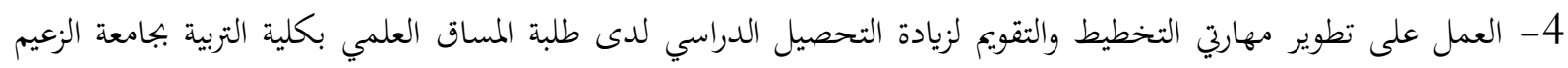
الأزهري. 


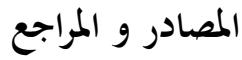 \\ أولاً: المراجع العربية}

أبو دنيا، نادية (2003)، أثر كل من التحصيل الأكاديمي وبعض خصائص الشخصية على تنظيم الوقت ودقة تقدير الأداء

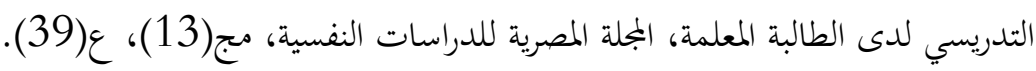

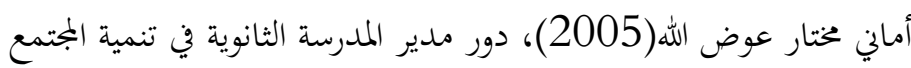

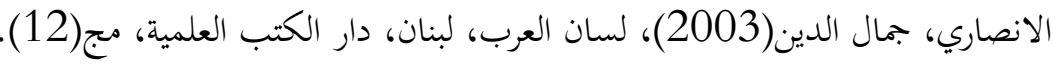

جامعة الزعيم الأزهري(2010)، منهج كلية التربية:خطة كلية التربية بكالوريوس الشرف، السودان، شركة مطابع السودان للعملة

$$
\text { المحدودة. }
$$

جامعة الزعيم الأزهري(2019)، أمانة الشؤون العلمية:دليل الطالب، السودان، دار جامعة الزعيم الأزهري للنشر.

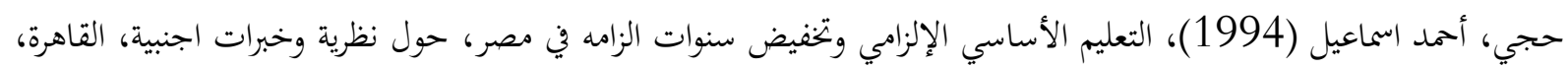

$$
\text { النهضة المصرية. }
$$

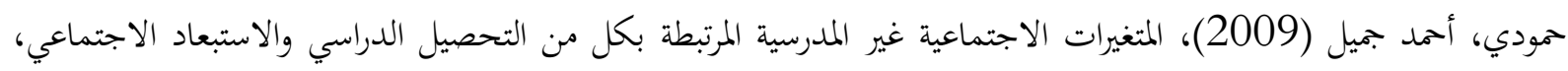

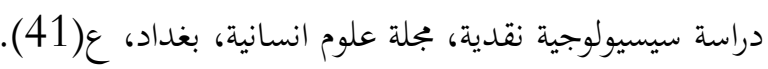

خلفان، فوزية(2011)، فاعلية برنامج ارشادي جمعي في تحسين مهارة تنظيم الوقت ورفع مستوى التحصيل لدى طلبة كلية العلوم

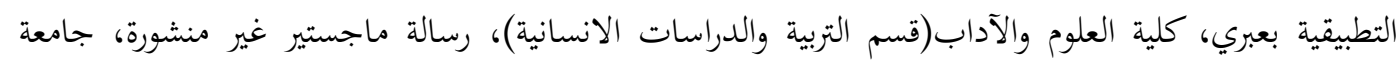

نزوى، سلطنة عمان.

خليل، نبيل سعد (1996)، فعالية إدارة الوقت من وجهة نظر مديري/ نظار مدارس التعليم العام: دراسة تحليلية ميدانية بمحافظة

$$
\text { سوهاج، كلية التربية بسوهاج، مصر. }
$$

الرحيمي، سالم و الماردينى، توفيق(2014)، أثر إدارة الوقت في التحصيل الأكاديمي للطلبة بجامعة إربد الأهلية (دراسة ميدانية

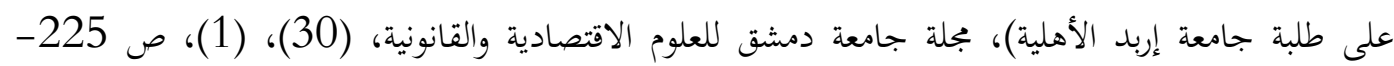

ص255.

سلامة، سهيل فهد (1988)، إدارة الوقت (منهج متطور للنجاح)، المنظمة العربية للعلوم والادارية، عمان، الأردن.

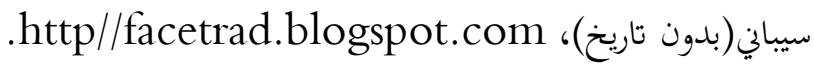
السيوف، أحمد علي (2014)، استراتيجيات إدارة الوقت لدى طلبة كلية العلوم التربوية في الجامعة الاردنية، مجلة دراسات العلوم

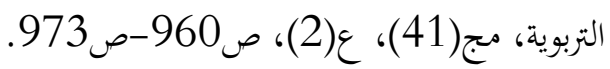

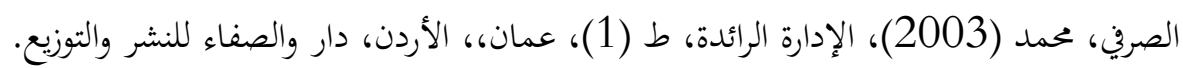

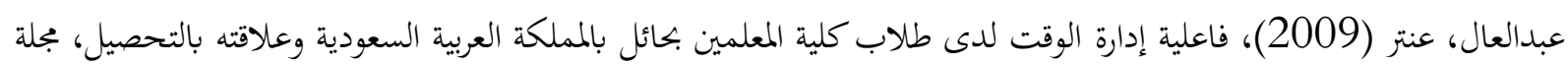

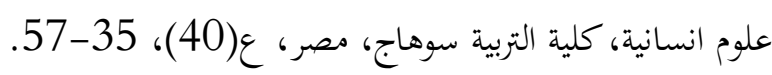

فخرو، حصة عبدالرحمن (2005)، مستويات إدارة الوقت لدى طالبات جامعة قطر وتخصصهن الجامعي في علاقتهما بالتحصيل

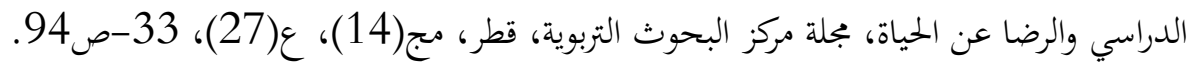

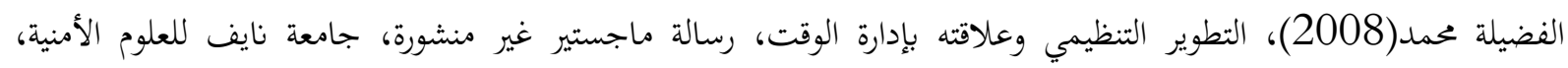

المحلي من وجهة نظر المعلمين وأولياء الأمور،، رسالة دكتوراه غير منشورة، كلية التربية، جامعة الزعيم الأزهري، الخرطوم. 
مراد، فاطمة(1995)، العوامل المؤثرة في إدارة الوقت لدى الادارات الوسطى في القطاع الاردني، رسالة ماجستير غير منشورة، جامعة اليرموك، اربد، الأردن.

المزين، سليمان حسن (2012)، فاعلية إدارة الوقت لدى طلبة الجامعة الإسلامية وعلاقتها بالتحصيل في ضوء بعض المتغيرات،

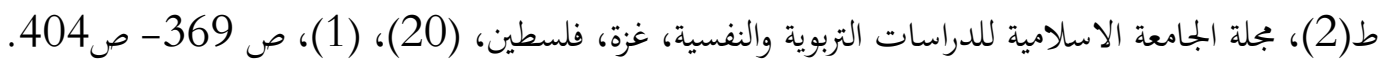

المومني، خالد (2017)، فاعلية إدارة الوقت لدى طلبة كلية العلوم في الجامعة الهاشمية وعلاقتها بالتحصيل الأكاديمي، مجلة المنار،

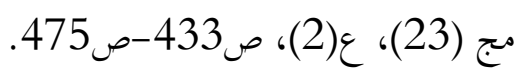

نامق، صابر نيان، (2015)، إدارة الوقت لدى طلبة الجامعة وعلاقته ببعض المتغيرات، مجلة أما راباك، مج(6)، ع(17)،

$$
\begin{aligned}
& \text { ص33- صاك } 50 . \\
& \text { ثانياً: المراجع الإنجليزية: }
\end{aligned}
$$

Cemaloglu ،Necati \& Filiz.(1996). The Relation Between Time management Skills and Academic Achievement Of Potential Teachers ،G a z I University ،Educational research Quarterly ،Vo 1(33)، (4) 3-23.

D alli ،M.(20014). The University students time management skills in terms of their academic satisfaction and academic achievement Levels. Education Review Journal ، ، 1090-1096.

D enlinger J.(2012). The Effects of management on college students academic Performance.PHD Dissertation ،Ball University ،USA. 